\title{
LÉXICO E TERRITÓRIO
}

\author{
Robervânia Lima de Sä \\ Leicijane da Silva Barros* \\ Luiz Roberto Peel Furtado de Oliveira**
}

RESUMO: No campo dos estudos lexicais, o conceito de território está presente em múltiplas dimensões e sentidos. Ele se verifica em documentos ou produtos como dicionários, glossários, vocabulários e também em pesquisas gerais que envolvem a palavra, isto é, a lexia. O presente artigo procura discutir o conceito de território, bem como sua utilização ou aplicabilidade à lexicologia sob a ótica de Bidermam (2001), Barbosa, (1981), Basílio (2004) e os filósofos Gilles Deleuze e Félix Guattari $(1974,1989,1992,1995,2004)$. A pesquisa é bibliográfica, de cunho qualitativo-explicativo e os resultados possibilitaram perceber a formação lexical como um território processual de transformações contínuas, isto é, um campo de perspectivas distintas que se desterritorializa e reterritorializa lentamente, sempre guiado por jogos de força e poder.

PALAVRAS-CHAVE: Desterritorialização; Léxico; Reterritorialização; Território.

\section{Introdução}

Estudar os conceitos de território no contexto da lexicologia representa um desafio considerável, sobretudo se as bases para tal empreendimento estiverem voltadas para a filosofia. Apesar disso, este foi nosso principal objetivo - discutir o conceito de território

* Mestre em Língua Portuguesa pela Universidade Federal do Tocantins. Doutoranda em Ensino de Língua e Literatura pela UFT. Professora efetiva do Instituto Federal de Educação, Ciência e Tecnologia do Pará (Ifpa).

${ }^{*}$ Doutoranda em Letras: Ensino de Língua e Literatura pela Universidade Federal do Tocantins (UFT). Mestre em Letras pelo Programa de Mestrado Profissional em Rede Nacional - (Profletras/UFT), Campus de Araguaína.

${ }^{* * *}$ Professor da Universidade Federal do Tocantins (UFT). Doutor e mestre em Letras pela Universidade de São Paulo (Usp). Realizou estágio de Pós-doutorado em Letras na Universidade da Beira Interior (Portugal - 2015, Bolsista Sênior CAPES) e em Letras Clássicas (Latim) no Laboratório de Letras Clássicas da Universidade Federal da Paraíba (2015). 
relacionando-o a lexicologia sob o olhar dos filósofos Gilles Deleuze e Félix Guattari (2004).

Notamos que a relação entre o conceito de léxico e o conceito filosófico de território é semelhante e aparente quando percebemos que ambos são fortemente influenciados pelas questões sociais, políticas, econômicas e históricas. Quando observamos que as transformações lexicais, isto é, os neologismos (surgimento de novas palavras ou novos conceitos para as preexistentes) representam domínio ou uma luta pelo poder, percebemos que tal crescimento, transformação ou surgimento de novas, não segue uma ordem comum, linear e previamente planejada, como as árvores que nascem, crescem, amadurecem, frutificam e morrem, mas dependem dos acontecimentos, isto é, da movimentação ou transformação social que, às vezes, fogem aos controles exercidos daqueles que se encontram no poder em determinado momento ou período. É devido a isso, que palavras consideradas em desacordo com a norma padrão passam a pertencê-la.

Estudar o léxico, levando em consideração o território, à luz de Deleuze e Guattari (2004), é explorar um universo de devires e rizomas que não respeitam o senso comum e fogem da linearidade até chegar a um universo paradoxal, isto é, a um universo que une o senso e o contrassenso ao mesmo tempo. Posto que, aqui, o território constitui-se como centro norteador das ações a serem engendradas pelas mudanças e transformações lexicais que ocorrem intrinsecamente associadas ao tempo e ao lugar em que as ações acontecem. Neste sentido, o léxico se torna uma estratégia de organização dos grupos sociais, considerando que as mudanças linguísticas não ocorrem de modo isolado.

Devido a isso, faz-se necessário perceber que o território passa por processos territorialização, desterritorialização e reterritorialização - que podem ser lógicos e ilógicos, que por vezes proporcionam emancipação e participação, ou o contrário, sujeição e dominação, e às vezes, as duas coisas ao mesmo tempo.

Dessa maneira, esta pesquisa procura apresentar, inicialmente, o léxico como sendo um campo científico, seus conceitos, bem como seu objeto de estudo, para em seguida, introduzir as noções conceituais de território que dependem da compreensão do que é 
devir e rizoma, concepções também exploradas no texto. Para finalizar, buscamos analisar o léxico sob a ótica dos conceitos de território procurando relacioná-los.

\section{Léxico: primeira ciência linguística}

Considerada como a ciência que estuda o processo de nomeação das coisas e seres, o léxico, é de fundamental importância para toda e qualquer sociedade. Assim, como não há sociedade sem nome, também não pode haver sociedade que não necessite explorar os conceitos lexicais. A prática de nomear seres e coisas é milenar. Um dos primeiros registros acerca dela se encontra na Bíblia - livro considerado sagrado pelos cristãos. A escrituração não deixa dúvidas de que a responsabilidade de nomear e classificar tudo que nos cerca pertence ao homem. Assim, desde as organizações sociais, bem como as religiosas, apontam para o fato de que desde a criação do universo o homem precisa nomear tudo que o cerca. A despeito disso, no livro de Gênesis (2:19-20) encontramos:

Sendo assim, o SENHOR modelou, do solo, todos os animais selvagens e todas as aves do céu e, em seguida, os trouxe à presença do homem para ver como este os chamaria; "e o nome que o homem desse a cada ser vivo, esse precisamente seria seu nome". E, desse modo, o homem nomeou a todos os animais: os rebanhos domésticos, as aves do céu e a todas as feras. (A BIBLIA, 2008, grifo nosso)

Biderman (2001) ratifica essa ideia afirmando que o processo de nomeação da realidade pode ser considerado a primeira etapa do percurso científico do ser humano rumo ao conhecimento do universo. Ao dar nome aos seres e objetos, classificando-os simultaneamente, o homem organiza de modo estruturado tudo que existe. Ao nomear, ele reúne objetos e seres em grupos que são organizados tendo como principal critério as semelhanças e diferenças.

Diante do exposto, compreende-se que uma das primeiras ciências da linguagem adotada pelo homem foi, indiscutivelmente, o léxico, uma vez que ele estuda sistematicamente o processo de nomeação que foi a primeira responsabilidade imposta ao homem por seu criador. Acerca desse assunto, Janson (2015, p. 14) afirma que "nomear os animais e, 
assim, inventar uma parte da língua foi a primeira atividade de Adão”. Ainda que o mesmo não possuísse a compreensão ou consciência de que estava fazendo uso de uma prática considerada científica na atualidade, ele estava praticando ciência.

A existência das coisas independe de nossa consciência acerca delas. O Dicionário On-line Aurélio (2018) apresenta muitos conceitos para ciência, dentre eles está: “4 - ciência infusa: conhecimentos adquiridos naturalmente, sem estudo, nem ensinamento”. Dessa forma, podemos afirmar que Adão praticava ciência no período da criação, pois possuía o conhecimento da prática de nomear.

Acerca do conceito de léxico, Biderman (1996) ainda afirma que:

O léxico é o lugar da estocagem da significação e dos conteúdos significantes da linguagem humana. Mais importante ainda: o léxico está associado ao conhecimento, e o processo de nomeação em qualquer língua resulta de uma operação perceptiva e cognitiva. (BIDERMAN, 1996, p. 27)

Essa percepção linguística acerca de léxico nos leva a considerarmos as funções da língua. A língua apresenta dupla função, posto que, ao passo que é um sistema de classificação também é um sistema de comunicação. Neste sentido, o papel do léxico se relaciona a essa dupla função da língua, visto que categoriza e armazena os elementos de designação que são as palavras, denominadas nesta pesquisa de lexias.

O léxico, portanto, não é apenas um conjunto de palavras. Como sistema dinâmico, apresenta estruturas a serem utilizadas em sua expansão. Essas estruturas, os processos de formação de palavras, permitem a formação de novas unidades no léxico como um todo e também a aquisição de palavras novas por parte de cada falante. (BASILIO, 2004, p. 7)

Em outras palavras, o léxico seria o conjunto que representa o patrimônio sociocultural de uma nação. "O reflexo do universo das coisas, das modalidades do pensamento, do movimento do mundo e da sociedade" (BARBOSA, 1981, p. 77), é tudo 
isso que proporciona a perpetuação e também o surgimento das lexias que representam os valores, crenças, costumes e inovações de uma comunidade.

Para Matoré (1953), o léxico pode ser definido como o testemunho da sociedade no seu modo de vida em uma determinada época, refletindo assim, os períodos históricos e sociais. Vilela (1995) ratifica as ideias de Matoré ao afirmar que o léxico é a parte geral, o social e o essencial.

A esse respeito, Ferraz (2006) acrescenta que o léxico é o componente da língua que mais recebe impactos advindos dos acontecimentos sociais e culturais, por isso, podemos notar por meio dele, as mudanças científicas e tecnológicas que ocorrem no mundo. Isto acontece devido ao caráter dinâmico da língua impor constante expansão lexical.

De uma maneira simplista, Picoche (1977, p. 44) afirma que léxico é "o conjunto das palavras de uma língua que estão à disposição dos falantes”. Basílio (2004) acrescenta que ele pode ser externo e mental. Dessa forma, o tesauro de uma língua representa seu léxico externo, enquanto que os conhecimentos acerca dos padrões estruturais necessários a interpretação e formação de novas lexias correspondem ao léxico mental. Nas palavras da autora, ele "é constituído por uma lista de formas já feitas e por um conjunto de padrões, os processos de formação de palavras, que determinam estruturas e funções tanto de formas já existentes quanto de formas ainda a serem construídas” (BASÍLIO, 2004, p. 8)

Todas as características acima nos permitem observar o léxico como um território científico de muitas nuances, conforme veremos a seguir.

\section{Território: noções conceituais}

O léxico pode ser considerado a partir da ótica do território, se levarmos em consideração os aspectos sociais, econômicos e políticos que se relacionam diretamente com ambos os campos, contudo, antes de nos aprofundarmos acerca da relação existente entre léxico e território, trataremos essencialmente do conceito de território, conforme indicado na introdução dessa pesquisa. 
A formulação de um conceito é uma construção complexa que, normalmente, fica a cargo da filosofia, a ciência que se preocupa em responder/questionar os porquês relativos a tudo que envolve a existencialidade. Melhor dizendo, ela possui como objeto de estudo as conceituações científicas, artísticas, religiosas e cotidianas. Assim sendo, para a filosofia,

O conceito é o contorno, a configuração, a constelação de um acontecimento por vir. Os conceitos, neste sentido, pertencem de pleno direito à filosofia, porque é ela que os cria, e não cessa de criá-los. O conceito é evidentemente conhecimento, mas conhecimento de si, e o que ele conhece é o puro acontecimento, que não se confunde com o estado de coisas no qual se encarna. Destacar sempre um acontecimento das coisas e dos seres é a tarefa da filosofia quando cria conceitos, entidades. Erigir o novo evento das coisas e dos seres, dar-lhes sempre um novo acontecimento: o espaço, o tempo, a matéria, o pensamento, o possível como acontecimentos [...]. (DELEUZE; GUATTARI, 1992, p. 46)

Conceituar, então, é uma tarefa específica da filosofia, devido a isso, o conceito de território se constrói tendo por base múltiplos objetos de estudo, uma vez que a filosofia perpassa por todos os campos possíveis e imagináveis.

Ele se organiza em torno de uma ideia que centraliza, reúne, associa e norteia classificações e/ou subdivisões epistemológicas em torno de um "lugar/campo" comum. Nesse contexto, em que as ciências que compõem, de maneira intrínseca, o lugar/campo comum - já que nenhuma delas poderia explorar isoladamente todas as peculiaridades desse território -, os estudos lexicais surgem como estratégias de organização do território a ser investigado.

Para compreendermos adequadamente o conceito de território, segundo Deleuze (1992), é importante conhecermos ainda outros conceitos que corroboram para tal empreendimento como o conceito deleuzeano para devir e rizoma. 


\section{Devir}

Devir - ou devenire em latim que significa chegar - está relacionado às mudanças constantes sofridas pelas coisas. Neste sentido, podemos depreender que a única constância existente no mundo é a inconstância, nada no mundo, com exceção da mudança e da transformação, é permanente. Heráclito, um dos filósofos que discute o conceito de devir, afirmava que "tudo flui e nada permanece, tudo dá forma e nada permanece fixo. Você não pode pisar duas vezes no mesmo rio, pois outras águas e ainda outras, vão fluir.” (JAPIASSÚ; MARCONDES, 1993, p. 72).

Em se tratando de devir, há sempre controvérsias. Para Platão, a teoria do devir não poderia invalidar as perspectivas de imutabilidade do ser, para ele, o devir é apenas objeto de opinião que é observado pelos sentidos e não pela razão. Ele se constitui na propriedade das coisas enquanto cópias, mimeses das ideias puras pertencentes à metafísica.

Por sua vez, Aristóteles (In: JAPIASSÚ; MARCONDES, 1993) afirma que devir é o princípio de atualização da potência em direção à realização da forma, isto é, o princípio do devir é o movimento, e o princípio do movimento é a potência do ato. O devir seria um estado intermediário para uma causa final. Neste caso, é quebrada aqui a ideia de um contínuo fluxo constitutivo ou territorial e destrutivo ou desterritorial, para dar a ideia de um ser encoberto pelo devir. Hegel (s/d) afirma que “o devir é a verdadeira expressão do resultado de ser e nada, como unidade destes: não é só a unidade do ser e do nada, mas é a inquietação em si” (HEGEL s/d, p. 268).

Para Gilles Deleuze (1992), a realidade se perfaz em uma zona não discernível onde as definições dos termos ou lexias de uma relação se formam pela própria relação que as une, de maneira dinâmica, recíproca e complexa, e é tudo isso que forma o devir. O conceito deleuzeano para devir lança sobre o homem a responsabilidade da construção do real e da valorização da diferença e da não continuidade.

De acordo com Deleuze e Guattari (1992):

Quando Foucault admira Kant por ter colocado o problema da filosofia não remetendo ao eterno, mas remetendo ao Agora, ele quer dizer que a filosofia não tem como objeto contemplar o eterno, nem 
refletir a história, mas diagnosticar nossos devires atuais: um devirrevolucionário que, segundo o próprio Kant, não se confunde com o passado, o presente nem o porvir das revoluções. Um devir-democrático que não se confunde com o que são os Estados de direito, ou mesmo um devir-grego que não se confunde com o que foram os gregos. Diagnosticar os devires, em cada presente que passa, é o que Nietzsche atribuía ao filósofo como médico, "médico da civilização" ou inventor de novos modos de existência imanentes. A filosofia eterna, mas também a história da filosofia, cedem lugar a um devir-filosófico. Que devires nos atravessam hoje, que recaem na história, mas que dela não provêm, ou antes, que só vêm dela para dela sair? (DELEUZE; GUATTARI, 1992, p. 144)

Dessa maneira, a maioria dos filósofos compreende o termo devir como um processo permanente de transformação ou mudança que todos os seres passam. O processo de criação, transformação e modificação presente em tudo que existe é o principal argumento que sustenta a teoria do devir como o processo do passar a ser ou vir a ser; tornarse ou transformar-se.

Os filósofos tinham por base dois caminhos para a percepção do real: o caminho da razão e o caminho dos sentidos. O caminho da razão está diretamente relacionado ao ser, no que ele é ou não é, contudo, o caminho dos sentidos está pautado no devir e na multiplicidade que se encontra no nível instável das opiniões e das convenções de linguagem (PESSANHA, 1996, p. 21). Assim sendo, o devir seria um não ser que representa, de certa maneira, um posicionamento contrário a visão de mundo sensitiva superficial e contribui para novas formas - formas paradoxais - que contrariam as convenções sociais de ver/sentir devires.

Em Deleuze (1974), a teoria do sentido é formada por paradoxos. O sentido, por sua vez, é uma entidade não existente, ele tem mesmo com o não senso relações muito particulares. O bom senso é a afirmação de que, em todas as coisas, há um sentido determinável; mas o paradoxo é a afirmação dos dois sentidos ao mesmo tempo. Dessa maneira, o paradoxo é afirmação do que é determinável e também do indeterminável - lógico e ilógico (DELEUZE, 1974), e tudo isto representa uma forma de devir. 
Devir é, a partir das formas que se tem, do sujeito que se é, dos órgãos que se possui ou das funções que se preenche, extrair partículas, entre as quais instauramos relações de movimento e repouso, de velocidade e lentidão, as mais próximas daquilo que estamos em vias de devir, e através das quais devimos. É nesse sentido que o devir é o processo do desejo. (DELEUZE; GUATTARI, 1974, p. 67)

O devir como processo de desejo se relaciona com as questões sociais. Para Deleuze, é viável "fazer a leitura do social desde o desejo, fazer a passagem do desejo ao político, nos quadros dos modos de subjetivação” (GUATTARI; ROLNIK, 1986, p. 16). Todos esses fatores nos fazem pensar o devir como algo agenciado.

Por causa disso, o devir/desejo constrói territórios por proporcionar diversos agenciamentos, nos fazendo concluir que o território é um agenciamento. O agenciamento tem como principal característica a abrangência, pois tudo pode ser agenciado. Assim, se tudo pode ser agenciado, tudo pode ser territorializado.

Dessa maneira, o devir/desejo é agenciado e o agenciamento é o caminho para a construção do território. Com base nesses pressupostos, passaremos a verificar o conceito de rizoma e sua relação com o conceito de território.

\section{Rizoma}

O conceito de rizoma, bem como todos os demais criados por Deleuze e Guattari (1995), é denominado por eles próprios de "teoria das multiplicidades", devido os autores levarem em consideração a/as realidade(s) dos seres, isto é, consciente e inconsciente, natureza e história, corpo e alma. Os autores admitem que subjetivações, totalizações e unificações são "processos que se produzem e aparecem nas multiplicidades". Contudo, enfatizam que as mesmas "não supõem nenhuma unidade, não entram em nenhuma totalidade e tampouco remetem a um sujeito" (DELEUZE; GUATTARI, 1995, p. 8), formando assim a principal característica do rizoma, a pluralidade, que desconsidera por completo a hierarquização da árvore-raiz. Para os filósofos, 
Qualquer ponto de um rizoma pode ser conectado a qualquer outro e deve sê-lo. É muito diferente da árvore ou da raiz que fixam um ponto, uma ordem. A árvore lingüística à maneira de Chomsky começa ainda num ponto $\mathrm{S}$ e procede por dicotomia. Num rizoma, ao contrário, cada traço não remete necessariamente a um traço lingüístico: cadeias semióticas de toda natureza são aí conectadas a modos de codificação muito diversos, cadeias biológicas, políticas, econômicas, etc., colocando em jogo não somente regimes de signos diferentes, mas também estatutos de estados de coisas. (DELEUZE; GUATTARI, 1995, p. 15)

Dessa maneira, tanto o conceito de devir quanto o de rizoma contribuem para compreendermos de modo adequado o pensamento dos filósofos. Ambos constroem suas teorias pautadas no modelo rizomático que propõe a construção do pensamento sem conceitos hierarquizados que partem de um ponto central de poder ou referência para a elaboração de outros conceitos; ao contrário, aqui, o rizoma age por meio de ligações múltiplas, ele está “voltado para uma experimentação ancorada no real” (DELEUZE e GUATTARI, 1995, p. 22), de maneira aberta e reversível, contrapondo-se "a lógica binária e as relações biunívocas" que "dominam ainda a psicanálise (...), a lingüística e o estruturalismo, e até mesmo a informática” (1995, p. 13) que se organizam de maneira arborescente, isto é, hierarquizada em torno de centros de poder.

Para Jordão e Fogaça (2012, p. 08) o pensamento rizomático e o arborescente podem ser descritos da seguinte maneira:

Quadro 1 - Comparativo entre árvore e rizoma.

\begin{tabular}{|l|l|}
\hline Árvore & Rizoma \\
\hline Estrutura & Sistema \\
\hline Genealogia & Antigenealogia \\
\hline Linearidade & Imprevisibilidade \\
\hline Hierarquia & Transgressão \\
\hline Ciclos com início, meio e fim & Intermežo \\
\hline Pivô central & Trama neural, multiplicidade \\
\hline Continuidade & Ruptura a-significante \\
\hline Reprodução, decalque & Mapas \\
\hline
\end{tabular}

Fonte: (Jordão e Fogaça, 2012, p. 08 - adaptado). 
Todas estas definições se relacionam com o conceito de território que se pretende examinar nesta pesquisa. Eles servirão de base para estudarmos, mais a frente, o conceito de léxico considerando-o um território, às vezes arborescente, às vezes rizomático.

\section{Léxico enquanto território}

O termo território, assim como, grande parte da língua portuguesa, origina-se do latim vulgar ou popular - territorium- e é derivado do substantivo terra que significa pedaço de terra apropriada (GONDIM e MONKEN, 2014). Contudo, no decorrer do tempo, o termo passou a apresentar múltiplos sentidos a partir de sua utilização em campos distintos da geografia. Assim sendo, "o território não é um dado neutro nem um ator passivo. [...] O espaço geográfico não apenas revela o transcurso da história como indica a seus atores o modo de nela intervir de maneira consciente" (SANTOS, 2001, p. 80).

Nos estudos lexicais, ele se relaciona, sobretudo, aos estudos que se preocupam com as questões filosóficas, políticas, sociais e geográficas ou onomasiológicas que proporcionam transformações linguísticas.

Para Guattari e Rolnik (1986),

A noção de território aqui é entendida num sentido muito amplo, que ultrapassa o uso que fazem dele a etologia e a etnologia. Os seres existentes se organizam segundo territórios que os delimitam e os articulam aos outros existentes e aos fluxos cósmicos. O território pode ser relativo tanto a um espaço vivido, quanto a um sistema percebido no seio da qual um sujeito se sente "em casa". O território é sinônimo de apropriação, de subjetivação fechada sobre si mesma. Ele é o conjunto de projetos e representações nos quais vai desembocar, pragmaticamente, toda uma série de comportamentos, de investimentos, nos tempos e nos espaços sociais, culturais, estéticos, cognitivos. A Geografia, a categoria território está relacionada à posse. (GUATTARI; ROLNIK, 1986, p. 323)

No campo da filosofia, o termo território é conceituado como uma construção provisória que se organiza em torno dos processos de desterritorialização e reterritorialização, isto é, “o território só vale em relação a um movimento através do qual dele se sai”. Uma 
vez que "não há território sem um vetor de saída do território, e não há saída do território, ou seja, desterritorialização, sem, ao mesmo tempo, um esforço para se reterritorializar em outra parte" (DELEUZE, 1989, p. 4).

O território pode ainda,

se desterritorializar, isto é, abrir-se, engajar-se em linhas de fuga e até sair do seu curso e se destruir. A espécie humana está mergulhada num imenso movimento de desterritorialização, no sentido de que seus territórios "originais" se desfazem ininterruptamente com a divisão social do trabalho, com a ação dos deuses universais que ultrapassam os quadros da tribo e da etnia, com os sistemas maquínicos que a levam a atravessar cada vez mais rapidamente, as estratificações materiais e mentais. (GUATTARI; ROLNIK, 1986, p. 323)

Nos estudos lexicológicos é possível vermos esse processo contínuo de desterritorialização e reterritorialização sofrido pelo território, em virtude da constante mudança sofrida pela língua. Todos os anos verificam-se neologismos distintos que surgem e compõem o patrimônio vocabular das diversas sociedades, como, por exemplo, a palavra "tuiteiro" que derivou do substantivo inglês Twitter e foi adaptada às normas da língua portuguesa. Para Santos (2001):

O território tanto quanto o lugar são esquizofrênicos, porque de um lado acolhem os vetores da globalização, que neles se instalam para impor sua nova ordem, e, de outro lado, neles se produz uma contraordem, porque há uma produção acelerada de pobres, excluídos, marginalizados. (SANTOS, 2001, p. 114)

$\mathrm{Na}$ lexicologia, as pesquisas que se preocupam com a adoção ou exclusão dos neologismos das classes subjugadas podem ratificar o conceito de território adotado pelo autor, uma vez que representam a produção acelerada dos pobres, excluídos e marginalizados, conforme é mencionado por ele no fragmento acima. Como exemplo, podemos mencionar as gírias adotadas pela população carente brasileira. Nelas podemos observar significados distintos daqueles adotados pela norma padrão da língua. A palavra animal, na norma padrão, significa reino biológico, contudo, na gíria, representa algo muito legal ou radical. 
Assim sendo, nesse contexto, o território passa a ser considerado categoria central, o que contraria a visão tradicional da geografia que perpetua a noção de território como sendo um objeto naturalmente estático.

No campo linguístico, ele é dinamicamente transformado por meio das inter-relações discursivas que ocorrem entre os falantes. Todos esses aspectos evidenciam a reciprocidade de influências entre território físico ou não e sociedade. Dessa forma, o território "seria formado pelo conjunto indissociável do substrato físico, natural ou artificial, e mais o seu uso, ou, em outras palavras, a base técnica e mais as práticas sociais, isto é, uma combinação de técnica e política” (SANTOS, 2002, p. 87). Devido a isto, não se pode separar o aspecto social, econômico e político do conceito de território. Dessa maneira,

As discussões mais recentes sobre território incorporam o componente cultural considerando que o território carrega sempre, de forma indissociável, uma dimensão simbólica, ou cultural em sentido estrito, e uma dimensão material, de natureza predominantemente econômico-política. (MOKEN, 2008, p. 5)

Diante do exposto, ao observarmos o léxico como um território, podemos compreendê-lo como sendo uma produção coletiva relacional de materialidade histórica, social, econômica, política e espacial de cada língua ou dialeto.

Neste sentido, o território seria de produção coletiva, porque, a língua ou tesauro, é, ao mesmo tempo, um produto social da faculdade da linguagem e um conjunto de conversões necessárias, adotadas pelo corpo social para permitir o exercício dessa faculdade nos indivíduos. A língua constitui-se como algo adquirido e convencional (SAUSSURE, 1994), isto é, um produto convencionalmente adquirido e desenvolvido coletivamente. As variações linguísticas do tipo "diafásicas", “diatópicas” e ”diastráticas” corroboram para tal afirmação, uma vez que dependem de fatores sociais como faixa etária, regionalismo, condição social, dentre outras.

O aspecto relacional do léxico enquanto território se justifica devido à interdependência que ocorre entre os surgimentos e as transformações das lexias - processo denominado neologismo. Transformação em decorrência de acontecimentos dos modos de viver 
e, consequentemente, de nomear e falar ou "o elemento resultante do processo de criação lexical" (ALVES, 2004, p. 5), com as regras que as subsidiam.

Para Sandman (1991, p. 14), os falantes possuem competência lexical e esta, por sua vez, "além de fixar regras que conduzem à formação de novas unidades, também limitam essas formações, gerando bloqueios e restrições de unidades não previstas pelo sistema linguístico", o que denota relação de dependência, causa e consequência, que reconfigura ou reterritorializa modelos sócios-culturalmente institucionalizados, objetivando proporcionar o novo com base no velho.

O território lexical apresenta ainda materialidade histórica paradoxal, isto é, ao mesmo tempo em que cria novas unidades linguísticas, deixa para traz elementos que caíram em desuso, denominados por Bechara (2006, p. 351) de arcaísmos.

Segundo Basílio (2004, p. 9), o sistema precisa ser aberto, expansível, para incorporar novas unidades criadas e, contrátil, para se redimensionar quando unidades que deixam de ser utilizadas não façam mais parte de seu conjunto. Todo esse movimento de ascensão e exclusão de lexia apresenta bom senso e representa um paradoxo.

Dessa forma, estudar o léxico segundo a lógica do território é observar as lexias que pulsam nos lugares que lhes são inerentes. Pensar nas influências que contribuem para formação das palavras em uma cidade interiorana é diferente de pensar em uma metrópole. Ambos representam territórios distintos histórico, social, econômico e politicamente. Há histórias que determinam os nomes e vice-versa.

Há histórias sociais que produzem marcas e formas peculiares de se expressar na mesma língua portuguesa, com palavras e sons particulares; modos de expressão cultural que revelam influências de diferentes culturas nas festas e celebrações, na culinária, na dança, na música; territórios com sua base econômica e formas de exploração do homem com suas consequências no modo de viver e levar a vida. (LIMA; YASUI, p. 598, 2014)

São todos estes aspectos que são considerados quando apreciamos o léxico como um território em constante transformação. Um território rizomático formado por um sistema múltiplo. 


\section{Considerações finais}

Conforme observado ao longo da pesquisa, a definição de território evoluiu ao longo dos anos. A princípio, referia-se apenas a terra apropriada, contudo, depois de sua exploração conceitual por parte da filosofia, ele abarca as diversas áreas do conhecimento, inclusive, a lexical, que constitui uma das primeiras ciências exploradas pelo homem.

Ao observarmos os aspectos do conceito de território, relacionando-o ao léxico, notamos que o território da lexicologia é composto por produções coletivas de materialidade histórica, social, econômica e política que atuam constantemente e em conjunto de forma relacional, uma vez que se refere à construção e à transformação, isto é, a territorialização e reterritorialização entre as lexias antigas e as oriundas das influências sociopolíticas produzidas pelo homem que nada mais são do que as memórias dos acontecimentos inscritas nas formas de falar e nomear tudo que nos cerca e que refletem as relações que emergem dos modos de apropriação e de alienação dessas influências, bem como dos valores contraditórios envolvidos, pois a língua, assim como o léxico - entendido como ciência que nomeia os seres -, serve de elemento de dominação. Como afirma Veríssimo, “dar nome às coisas é possuí-las, a colonização começa pela linguagem. Depois se destroem nações inteiras e se vira a história dos outros de cabeça para baixo." (VERÍSSIMO, s/d). Em outras palavras, dar nomes as coisas é territorializá-las.

\section{LEXICON AND TERRITORY}

ABSTRACT: In the field of lexical studies, the concept of territory is present in multiple dimensions and senses. It is verified in documents or products such as dictionaries, glossaries, vocabularies and also in general searches involving the word, ie lexia. This article discusses the concept of territory as well as its use or applicability to lexicology from Bidermam (2001), Barbosa (1981), Basílio (2004) and the philosophers Gilles Deleuze and Félix Guattari (1974, 1989, 1992, 1995, 2004). The research is bibliographical, qualitative and explanatory, and the results made it possible to perceive lexical formation as a processual territory of continuous transformations, that is, a field of distinct perspectives that is slowly deterritorialized and re-territorialized, always guided by games of power and power.

KEYWORDS: Desterritorialization; Lexicon; Reterritorialization; Territory. 


\section{REFERÊNCIAS}

A BÍBLIA. Gênesis. Tradução de João Ferreira Almeida. Rio de Janeiro: King Cross Publicações, 2008.

ALVES, I. M. Neologismo - criação lexical. 2. ed. São Paulo: Ática, 2004.

BARBOSA, M. A. Léxico, produção e criatividade. São Paulo: Global, 1981.

BASÍLIO, M. Formação e classes de palavras no português do Brasil. São Paulo: Contexto, 2004.

BECHARA, E. Moderna gramática portuguesa. Rio de Janeiro: Nova Fronteira, 2009.

BIDERMAN, M. T. C. Léxico e vocabulário fundamental. Alfa (UNESP), v. 40,1996.

. Teoria linguística (Teoria lexical e linguística computacional). São Paulo: Martins

Fontes, 2001.

DELEUZE, G.; GUATTARI, F. Post-scriptum sobre as sociedades de controle. In: DELEUZE, G. Conversações. Rio de Janeiro: Ed. 34, 1992.

- O que é a Filosofia? Rio de Janeiro: Ed. 34, 1992.

. Mil Platôs: capitalismo e esquizofrenia. Vol.1.Rio de Janeiro: 2004.

- Mil Platôs: capitalismo e esquizofrenia. Vol.1. Rio de Janeiro: 1974.

- Mil Platôs: capitalismo e esquizofrenia. Vol.3. Rio de Janeiro: 1995.

. Mil Platôs: capitalismo e esquizofrenia. Vol.3. Rio de Janeiro: 1989.

FERRAZ, A. P. A inovação lexical e a dimensão social da língua. In: O léxico em estudo. Belo Horizonte: UFMG, 2006.

FERREIRA, A. B. H. Dicionário Aurélio da língua portuguesa. Disponível em: < https://dicionariodoaurelio.com/ciencia.> Acesso em: 19 mar. 2018.

GUATTARI, F.; ROLNIK, S. Micropolítica: cartografias do desejo. Petrópolis: Vozes, 1986.

GONDIM, G. M. M.; MONKEN, M. Territorialização em saúde. Disponível em: <http://www.epsjv.fiocruz.br/upload/d/territorializacao_dicionario.pdf.> Acesso em: 18 mar. 2018.

HAESBAERT, R. 1994. O mito da desterritorialização e as "regiões-rede". Anais do $5^{\circ}$ Congresso Brasileiro de Geógrafos. Curitiba: s/d.

1997.

. Des-territorialização e identidade: a rede "gaúcha" no Nordeste. Niterói: EdUFF,

HEGEL. G. W. F. (S/D). In: ABBAGNANO, N. Dicionário de filosofia. 21ª Edição. Tradução: Alfredo Bosi. São Paulo, SP: Martins Fontes, 1998. 
JANSON, T. A história das línguas. São Paulo: Parábola editorial, 2015.

JAPIASSÚ, H.; MARCONDES, D. Dicionário básico de filosofia. Zahar; 1993.

LIMA, E. M. F. A.; YASUI, S. Territórios e sentidos: espaço, cultura, subjetividade e cuidado na atenção psicossocial. Disponível em: <www.scielo.br/pdf/sdeb/v38n102/0103-1104sdeb-38-102-0593.pdf> Acesso em: 12 dez. 2017.

MATORÉ, G. La Méthode en Lexicologie: domaine français. Paris: Marcel Didier, 1953.

MOKEN, M. (2008). In: LIMA, E. M. F. A.; YASUI, S. Territórios e sentidos: espaço, cultura, subjetividade e cuidado na atenção psicossocial. 2014. Disponível em: <www.scielo.br/ pdf/sdeb/v38n102/ 0103-1104-sdeb-38-102-0593.pdf> Acesso em: 12 dez. 2017.

PESSANHA, J. A. M. As delícias do Jardim. In. NOVAES, A. (Org.) et al. Ética. São Paulo: Companhia das Letras: Secretaria Municipal de Cultura, 1992.

tras, 2007.

. As delícias do jardim. In. NOVAES, A. (org.) Ética. São Paulo: Companhia das Le-

PICOCHE, J. Précis de Lexicologie Française: l' etude et l'enseignement du vocabuláire. Paris: Nathan Université, 1977.

SANDMANN, A. J. Competência lexical. São Paulo: Editora da UFPR, 1991.

SANTOS, M.; SILVEIRA, M. L. O Brasil: território e sociedade no início do século XXI. Rio de Janeiro: Record, 2001.

. O país distorcido. In: RIBEIRO, W.C. (Org.). São Paulo: Publifolha, 2002.

SAUSSURE, F. Curso de linguística geral. São Paulo: Cultrix, 1994.

SAVITT, S. Being and Becoming in Modern Physics. Stanford Encyclopedia of Philosophy. 2013.

VERÍSSIMO, L. F. O nome das coisas. Disponível em: < http://noblat.o globo.globo.com/ cronicas/noticia/2017/06/o-nome-das-coisas.html> acesso em: 12 dez 2017.

VILELA, M. Estudos de lexicologia do português. Coimbra: Almedina, 1994.

Recebido em: 12/09/2019.

Aprovado em: 15/01/2019. 